\title{
The influence of infertility on sexual and marital satisfaction in Iranian women with polycystic ovary syndrome: a case-control study
}

\author{
Seyed-Abdolvahab Taghavi ${ }^{1}$, Shahintaj Aramesh ${ }^{2}$, Maryam Azizi-Kutenaee ${ }^{3}$, Helen Allan ${ }^{4}$, Tahereh Safarzadeh ${ }^{5}$, \\ Mojgan Taheri ${ }^{5}$, Shohreh Salari ${ }^{5}$, Zahra Khashavi ${ }^{6}$ and Fatemeh Bazarganipour ${ }^{7^{*}}$
}

\begin{abstract}
Background: The purpose of the present study was to evaluate sexual and marital satisfaction in couples with polycystic ovary syndrome (PCOS). A case-control study was conducted on 90 couples with PCOS and 90 healthy couples as a control group. Three measures were used to evaluate sexual function and marital satisfaction: the female sexual function index (FSFI), the Larson sexual satisfaction, and the ENRICH marital satisfaction measures.

Results: The results of this study show that the mean scores of sexual function, sexual satisfaction, and marital satisfaction were significantly lower in PCOS couples compared with the control group $(P<0.05)$. Infertility was reported as the strongest predictive factor for sexual function and marital satisfaction in couples with PCOS $(P<$ 0.05). Compared to the control group, sexual and marital satisfaction was lower in patients with PCOS and their partners.
\end{abstract}

Conclusion: Since infertility is the strongest predictive factor for the sexual health of couples with PCOS and sexual health is important in family health and marital life, sexual counseling may prove beneficial for these patients.

Keywords: Polycystic ovary syndrome, Sexual function, Sexual satisfaction, Marital satisfaction

\section{Background}

Polycystic ovary syndrome (PCOS) is the most common endocrine disease affecting women of childbearing age [1]. The prevalence of PCOS is estimated at 4.4-19.5 percent in Iran [2].

PCOS has many of the symptoms of pain, inconvenience, and unpredictability, with features that are culturally considered as non-feminine and undesirable such as hirsutism, acne, and amenorrhea [3]. Since PCOS often occurs at the same age as men and women seek to find a sexual partner, it is possible that self-confidence in one's appearance and psycho-sexual issues may cause

\footnotetext{
* Correspondence: f.bazarganipour@gmail.com

${ }^{7}$ Medicinal Plants Research Center, Yasuj University of Medical Sciences, Yasuj, Iran

Full list of author information is available at the end of the article
}

serious problems in these women who may feel undesirable $[4,5]$. Women with PCOS may feel that they are less attractive to their partner and that their partner is less satisfied with their relationship [6]. De Frène et al. [7] showed that sexual and marital satisfaction in couples with PCOS is affected by the symptoms associated with PCOS such as acne, a higher BMI than their peers, and infertility. However, De Frène et al.'s sample was a limited number of patients with PCOS and without considering a control group [7].

Sexual satisfaction is defined as individuals' perceptions of their pleasurable sexual behavior and is an individual need associated with human, social, and societal health [8]. Sexual dissatisfaction can affect individuals' health and reduce their ability to perform daily activities and be creative [9]. It may also affect their health and 
well-being; for example, research shows that the incidence of heart attacks is significantly decreased in men who experience sexual satisfaction in their marital life. Similarly, women find that sexual satisfaction reduces migraine and the incidence of headache, premenstrual syndrome, and chronic arthritis. Anxiety, lower abdominal pain, an inability to concentrate, and even an inability to perform common tasks are other reported consequences of failure to satisfy sexual needs in men and women [9].

Satisfaction of an individual's sexual needs is therefore an important factor in physical and mental health and strengthens family life. Because of the high prevalence of PCOS and its sexual and psychological sequels as well as the social consequences of sexual dissatisfaction, the aim of this study is to evaluate sexual and marital satisfaction in couples with PCOS compared with a control group. The findings are intended to assist in screening sexual and marital satisfaction in patients with PCOS and setting treatment goals in clinic and primary care.

\section{Methods}

\section{Design and data collection}

The present study is a case-control study. The case group included women with PCOS referred to an infertility clinic in Omelila Hospital in Hormozgan province in Iran from April 2015 to April 2016. This is the only infertility clinic in Hormozgan. The control group was also consistent with healthy married women within the age range of 18-45 who had no chronic disease, had a regular menstrual cycle, and they were selected from patients' companions by convenience sampling method.

Patients were eligible if they met each of the following criteria: desire to participate in the study, being 18-45 years of age, married, Iranian, having two of the following Rotterdam diagnostic criteria [10]: (1) polycystic ovaries visualized on ultrasound scan (presence of 12 follicles or more in one or both ovaries and/or increased ovarian volume, i.e., > $10 \mathrm{ml}$ ), (2) clinical signs of hyperandrogenism (hirsutism score based on hirsutism score greater than 7 or obvious acne) or chemical hyperandrogenism, (3) having an interval between menstrual periods > 35 days and/or amenorrhea, defined as the absence of vaginal bleeding for at least 6 months (i.e., 199 days). However, it should be noted we used only clinical signs for this study as our previous studies [1113]. Our exclusion criteria were as follows: having nonclassic adrenal hyperplasia, thyroid dysfunction, hyperprolactinemia, smoking, problems in speaking or listening, taking any prescription medication (except allergy medications and occasional pain medications) for at least 3 months before entering the study, severe psychological stress at least 3 months before entering the study (loss of relatives, etc.), history of taking psychiatric medications at least 3 months before entering the study, having score $<12$ according to International index of erectile function to both groups.

According to Drodzol et al., as $\alpha=0.05, \beta=0.2, \mu 1$ (mean score of sexual satisfaction in PCOS group) = 20.7; $\mu 2$ (mean score of sexual satisfaction in the control group) $=13.8$; S1 (standard deviation score of sexual satisfaction in PCOS group) $=18.5$; $\mathrm{S} 2$ (standard deviation score of sexual satisfaction in the control group) $=10.4$; sample size was estimated at 90 couples per group (a total of 360 persons) [14].

$$
n=\frac{\left(Z_{1-\alpha / 2}+Z_{1-\beta}\right)^{2}\left(S_{1}^{2}+S_{2}^{2}\right)}{\left(\mu_{1}-\mu_{2}\right)^{2}}
$$

\section{Measures}

1. Menstrual history: women were asked about the interval of two menstrual cycles in the last 12 months; their menstrual cycles were classified as follows: < 21 days, 21-34, 34-60, > 199 days, and irregular.

2. BMI: this variable was estimated by dividing each patient's weight by height ${ }^{2}\left(\mathrm{~kg} / \mathrm{m}^{2}\right)$.

3. Hirsutism: hirsutism scoring was based on the Gallwey scale (1961). Hutch et al. [15] modified this scoring system and limited it to 9 androgensensitive areas; each area based on the growth of terminal hair scored from $0-4$. A score of 7 or more indicated hirsutism [16].

4. Acne: Global Acne Grading Scale (GAGS) was assessed to measure acne. This scale considers six areas of the face, chest, and upper back to measure the level of involvement, distribution, density, and pilosebaceous units. Each of the six areas scores from 0-4 with the most severe lesion in each area determining the score of that area; the score of each region is multiplied by the factor score. The factor score is calculated according to the area involved: forehead, 2; left and right cheek, 2; nose, 1; chin, 1; and chest and upper back, 3 . The total score is obtained by multiplying the factor score by total score of involved area [17].

5. Sexual function: taken as impairment of sexual desire and arousal, dyspareunia, and orgasmic dysfunction. The questionnaire of female sexual function index (FSFI) was used in the present study to evaluate sexual function. FSFI was developed by Rosen et al. to evaluate sexual function over a 4week period. The 19 items questionnaire measures female sexual function in six independent dimensions indulging sexual desire (four items), arousal (four items), lubrication (four items), orgasm (three 
items), satisfaction (three items), and pain (three items). The answers are rated from zero to five where a higher score indicates more satisfactory sexual function [18]. The reliability and validity of the questionnaire are approved in Iran [19]. This questionnaire was completed by female participants.

6. Marital satisfaction: An ENRICH (evaluation and nurturing relationship issues, communication, and happiness) marital satisfaction scale was used to measure marital satisfaction. This questionnaire consisted of 47 questions which are classified as a Likert spectrum (1-5). A higher score indicates a higher level of marital satisfaction. The reliability and validity of the questionnaire have been approved in Iran, previously [20]. This questionnaire was completed by the couple.

7. Sexual satisfaction: to measurement this item, we used the Larson questionnaire which consists of 25 questions. The responses are rated as never (1) to always (5). The higher score indicates more sexual satisfaction. The reliability and validity of the questionnaire have been approved in Iran, previously [21, 22]. This questionnaire was completed by the couple.

8. International index of erectile function: a reliable self-report measure including five questions for assessment of sexual dysfunction in males. The answers are rated from one to five based on the Likert spectrum. The scores of less than 12 were considered as erectile dysfunction and excluded from the study. The reliability and validity of the questionnaire have been approved in Iran, previously [23].

Infertility is defined in this paper is by the World Health Organization as "a disease of the reproductive system defined by the failure to achieve a clinical pregnancy after 12 months or more of regular unprotected sexual intercourse" [24].

\section{Data analysis}

In the present study, we used descriptive and analytic statistics using SPSS 21. Data are presented as mean (standard deviation) for quantitative variable and $n$ (\%) for qualitative variable. In order to make comparison between groups, $T$ test was used for quantitative and Mann-Whitney test for ordinal variables. Information entered into regression models was limited to patients with PCOS and their spouses. Marital and sexual satisfaction were measured separately for females, males, and then the couple's scores were added. The mean total score of couples as a result was included in the regression model. In sexual function, only women's scores were measured. The variables listed in Table 2 were entered into the model as predictors. Significant levels of $P$ values less than 0.05 (typically $\leq 0.05 \%$ ) were acceptable. The $R$ square for all regressions presented in Tables 3 and 4 was $>0.70$. Linear regression was used to determine the most important predictors for sexual function, sexual, and marital satisfaction in couples with PCOS. Preparation of this manuscript was in accordance with the STROBE guidelines for observational studies.

\section{Results}

\section{The study samples}

In this study, 104 control subjects and 99 case groups were invited to participate in the study. In the case group, 3 people refused to participate in the study, 2 people used psychiatric drugs, and 4 people had an abnormal score in the International Erectile Dysfunction Index. In the control group, 6 people refused to take the participation, 2 people had abnormal scores in the International Erectile Dysfunction Index, 3 people had hypothyroidism and were taking drugs, 2 people were non-smokers, and 1 person was not Iranian. There were no missing values. Therefore, no missing imputation technique was used.

In total, 180 couples participated in the study over 1 year. Socio-demographic and clinical characteristics of patients are presented in Table 1 . There were no significant differences between the two groups in terms of the abovementioned characteristics except for acne score, hirsutism score $(P<0.05)$.

As mentioned in the "Methods" section, the control group consisted of healthy married women with regular menstrual cycles. Therefore, the information about infertility history and menstrual history for PCOS group is as follows: 60 (66.66\%) and 53 (58.88\%) of PCOS group had infertility and menstrual irregularities, respectively (menstrual interval < 21 days, 34-60, > 199 days, and irregular), respectively.

\section{Comparison of sum score of sexual function and satisfaction between couples with PCOS and control group}

The findings of Table 2 show that all dimensions of sexual function were significantly poor in the PCOS group compared with control group $(P<0.05)$. Moreover, patients with PCOS reported significantly lower sexual and marital satisfaction than the control group $(P<0.05)$. The scores of sexual and marital satisfaction reported were significantly lower in partners of PCOS patients compared with the control group $(P<0.05)$ (Table 2$)$.

\section{Predictive factors of sexual function and satisfaction in PCOS patients and their partners compared with control group}

The findings in Table 3 show that infertility is the strongest predictor for sexual satisfaction $(\beta=8.08, P<$ 
Table 1 Socio-demographic and clinical characteristics of participants

\begin{tabular}{|c|c|c|c|c|}
\hline \multicolumn{2}{|l|}{ Variable $^{a}$} & PCOS group $(n=90)$ & None PCOS group $(n=90)$ & $P$ value \\
\hline \multicolumn{2}{|c|}{ Age of patients (years) ${ }^{a}$} & $28.8 \pm 4.39$ & $30 \pm 4.83$ & 0.83 \\
\hline \multicolumn{2}{|c|}{ Age of partner (years) ${ }^{a}$} & $33.46 \pm 6.2$ & $35.26 \pm 6.24$ & 0.90 \\
\hline \multirow[t]{3}{*}{ Education $^{\mathrm{b}}$} & Guidance school or less & $16(17.77)$ & $13(14.44)$ & \multirow[t]{3}{*}{0.44} \\
\hline & Completed high school & $46(51.11)$ & $54(60)$ & \\
\hline & College & $28(31.11)$ & $23(25.55)$ & \\
\hline \multicolumn{2}{|c|}{$\mathrm{BMI}(\mathrm{kg} / \mathrm{m} 2)^{\mathrm{a}}$} & $24.99 \pm 3.72$ & $25.04 \pm 3.38$ & 0.91 \\
\hline \multicolumn{2}{|l|}{ Acne score ${ }^{c}$} & $8(2-16)$ & $3(1-7)$ & $<0.001$ \\
\hline \multicolumn{2}{|l|}{ Parity ${ }^{c}$} & $1(0-3)$ & $1(0-2)$ & 0.06 \\
\hline \multicolumn{2}{|c|}{ Hirsutism score ${ }^{c}$} & $9(1-15)$ & $3(0-5)$ & $<0.001$ \\
\hline
\end{tabular}

${ }^{\mathrm{a}}$ Mean \pm SD (standard deviation)

${ }^{\mathrm{b}}$ Number(\%)

cMedian (range)

$0.001)$ and marital satisfaction $(\beta=8.08, P<0.001)$ in patients with PCOS and their partners. Other important predictive factors for sexual and marital satisfaction were BMI, acne score, and the age of men $(P<0.05)$.

The findings in Table 4 demonstrate that infertility is the strongest predictive factor for sexual function $(\beta=$ $0.36, P<0.001)$, sexual satisfaction $(\beta=14.42, P=$ $0.001)$, and marital satisfaction $(\beta=5.27, P=0.05)$ in women with PCOS. Also, the age of patient was a predictive variable for sexual function $(\beta=0.2, P=0.05)$ in these patients (Table 4).

\section{Discussion}

Our finding in patients with PCOS showed lower levels of sexual function, sexual and marital satisfaction compared with the control group. This is similar to Masson et al. (2011) who reported lower sexual satisfaction in patients with PCOS. In Masson et al.'s study, sexual satisfaction was assessed by structured interview covering a variety of aspect of sexuality and McCoy questionnaire of female sexual satisfaction [25]. Kowatczyk et al.'s results have been shown that women with PCOS feel a lack of attraction to their partner more than a control group [26]. Elsenbruch et al. reported that women with PCOS felt less satisfied with their sexual life over the past 1 month. They also felt their partner is less satisfied with their relationship. However, in Elsenbruch et al.'s study, sexual function was measured only by the FSFI questionnaire [6].

Our finding indicated that infertility was the strongest predictive factor for sexual and marital satisfaction in PCOS. Also, as in the study by Hashemi et al., infertility was the strongest predictive factor for sexual dysfunction in Iranian patients with PCOS [27]. In the Iranian society, a women's infertility is very important; Iranian infertile women are under great social pressure for child bearing [28]. The finding is similar with the study of Winkvist and Akhtar in which Muslim Pakistan women reported that without having children they do not sense similar to a real woman [29]. In Iran, this is due to the role of parents and relatives of the couple's marital life is more complicated consequences [30-32]. With any

Table 2 Comparison of sum scores of sexual function and satisfaction between participants

\begin{tabular}{|c|c|c|c|c|}
\hline \multicolumn{2}{|l|}{ Variable $^{a}$} & PCOS group $(n=90)$ & None PCOS group $(n=90)$ & $P$ value \\
\hline \multicolumn{2}{|c|}{ Sexual satisfaction in women } & $100.03 \pm 8.87$ & $105.1 \pm 5.91$ & 0.05 \\
\hline \multicolumn{2}{|c|}{ Sexual satisfaction in partner } & $99.7 \pm 9.72$ & $104.9 \pm 7.22$ & 0.04 \\
\hline \multicolumn{2}{|c|}{ Marital satisfaction in women } & $105.7 \pm 2.41$ & $109.66 \pm 4.56$ & 0.05 \\
\hline \multicolumn{2}{|c|}{ Marital satisfaction in partner } & $100.94 \pm 5.59$ & $108.32 \pm 3.86$ & 0.03 \\
\hline \multicolumn{2}{|c|}{ Sum score of FSFI } & $26.32 \pm 2.76$ & $29.84 \pm 2.58$ & $<0.001$ \\
\hline \multirow[t]{6}{*}{ Domain of FSFI } & Desire & $4.3 \pm 0.68$ & $4.4 \pm 0.73$ & 0.05 \\
\hline & Arousal & $4.19 \pm 0.79$ & $4.49 \pm 0.82$ & 0.01 \\
\hline & Lubrication & $4.26 \pm 0.81$ & $5.37 \pm 0.46$ & 0.01 \\
\hline & Orgasm & $4.44 \pm 0.65$ & $4.85 \pm 0.55$ & $<0.001$ \\
\hline & Satisfaction & $5.46 \pm 0.59$ & $5.8 \pm .35$ & $<0.001$ \\
\hline & Pain & $3.58 \pm 1.08$ & $4.93 \pm 0.83$ & $<0.001$ \\
\hline
\end{tabular}

${ }^{a}$ Values are as mean \pm SD (standard deviation) 
Table 3 Predictive factors of marital and sexual satisfaction in couples with PCOS

\begin{tabular}{llllll}
\hline Outcome $^{*}$ & Predictive factors & $\boldsymbol{\beta}$ & $\mathrm{Cl}$ & $\boldsymbol{P}$ value & $\mathrm{SE}$ \\
\hline Sexual satisfaction & Infertility & 8.08 & $4.1-12.02$ & $<0.001$ & 1.98 \\
& Acne & 0.43 & $0.17-0.68$ & 0.001 & 0.12 \\
& BMl & 0.89 & $0.41-1.37$ & 0.05 & 0.24 \\
& Partner age & 0.21 & $0.18-0.8$ & 0.01 & 0.34 \\
Marital satisfaction & BMl & 1.45 & $0.61-2.29$ & 0.001 & 0.42 \\
& Partner age & 0.99 & $0.24-1.74$ & 0.01 & 0.37 \\
& Acne & 0.69 & $0.47-1.6$ & 0.003 & 0.52 \\
& infertility & 13.82 & $6.7-20.89$ & 0.01 & 3.55
\end{tabular}

SE standard error, $\mathrm{Cl}$ confidence interval

* $P$ values $\leq 0.05$ were considered as significant

delay in pregnancy, the worries, curiosity, pressures, and interventions of others begin, and individuals typically experience significant psychological and psychological stress, leading to some form of mental disorder [33-36]. Infertility affects not only the couple but also their family and friends. So, infertility is one of the worst life experiences and backgrounds and social conditions can also affect its pair, so it turns into a personal crisis [3739].

Although women with PCOS have hyper androgenic blood results, the scores of all dimensions of sexual function in patients with PCOS were significantly lower compared to the control group described with infertility. Hashemi et al. (2014) also suggested that infertile patients with PCOS showed more sexual dysfunction than fertile women with PCOS that was significant in all dimensions except for pain and desire [27]. When pregnancy does not occur, the meaning of sexual intercourse may change; largely because one of the important purposes of sexual function in some cultures and in some religions is to have children. The feeling that sexual activity is ineffective may reduce sexual desire in some couples. The cycle of increasing and decreasing hope in every month trying to treat PCOS-related infertility also causes stress which also affects sexual health. On the other hand, infertile women report that they merely perceive sexual intercourse as compulsion rather than a pleasure action. This changes their attitude toward sexual intercourse, causes stress while sexual intercourse and they may abstain to have sex. Hence, infertilityassociated tensions, expensive, and sometimes invasive treatment can act as a catalyst that reveals sexual problems. The importance of the problem is more evident when sexual problems could ultimately intensify infertility by reducing the frequency of coitus [40, 41]. The findings from Song et al.'s study (2014) are similar to our study, reporting low levels of sexual satisfaction in infertile couples compared with fertile couples [42]. However, Iris et al. have reported no important difference in sexual satisfaction between infertile women and a control group [41].

The present study shows that BMI is not the predictive factor of sexual and marital satisfaction in patients with PCOS; this finding is similar to Elsenburch et al. and Stovall et al. in which there was no relationship between BMI and the level of sexual satisfaction in patients with PCOS $[6,43]$. However, the present study is similar to Mansson et al. showing a significant association between increased BMI and decreased sexual satisfaction in women with PCOS [25]. In this study, the factors associated with appearance and beauty such as BMI and acne were more important for the partner than patients with PCOS. Since weight loss is the first and the most important step in treatment of PCOS and since this is usually ignored by patients because they think this is not very important, more attention should be given to BMI while presenting primary care for these patients.

Our study has several strengths including a greater sample size using standard measures for accurate assessment of sexual and marital health of couples and the inclusion in the design of a control group for comparison. There were limitations to the present study. Our study was limited to sampling from an infertility clinic. In our results, "infertility" is reported to be the strongest predictor of sexual and marital health. However, not all patients in the PCOS group have infertility and may present with other PCOS-related causes (e.g., menstrual irregularities) that affect the results. Generalization is therefore limited to the entire PCOS population. In addition, all patients participating in this study were married and Islamic. Also, we did not evaluate psychiatric complications. In addition to infertility, PCO has many psychiatric side effects, including depression and

Table 4 Predictive factors of marital and sexual satisfaction and function in women with PCOS

\begin{tabular}{|c|c|c|c|c|c|}
\hline Outcome* & Predictive factors & $\beta$ & $\mathrm{Cl}$ & $P$ value & $\overline{\text { SE }}$ \\
\hline \multirow[t]{2}{*}{ Sexual function } & Woman age & 0.2 & $0.005-0.42$ & 0.05 & 0.1 \\
\hline & Infertility & 0.36 & $0.19-0.53$ & $<0.001$ & 0.08 \\
\hline Sexual satisfaction & Infertility & 5.27 & $0.16-10.71$ & 0.05 & 2.73 \\
\hline Marital satisfaction & Infertility & 14.42 & $3.21-25.63$ & 0.01 & 5.6 \\
\hline
\end{tabular}


anxiety, which may affect sexual and marital satisfaction regardless of infertility. This may limit the association between infertility and sexual and marital satisfaction in these patients.

Further studies are employed with larger sample sizes than the less homogenous population, which allows for comparisons in culture and religious affiliation.

\section{Conclusions}

Compared to the control group, patients with PCOS showed poor sexual function and lower levels of sexual and marital satisfaction. According to our findings, infertility was the strongest predictive factor for the sexual health of couples with PCOS.

\section{Abbreviations \\ PCOS: Polycystic ovary syndrome; FSFI: Female sexual function index; GAGS: Global Acne Grading Scale; ENRICH: Evaluation and nurturing relationship issues, communication, and happiness}

\section{Acknowledgements}

Not applicable.

\section{Authors' contributions}

FB contributed in conception, design, statistical analysis, and drafting of the manuscript. MA, SAT, TS, MT, SS, ZKH, and HA contributed to data collection and manuscript drafting. SAT contributed to statistical analysis in the revision version of the manuscript and prepared the final version. All authors approved the final version for submission. FB supervised the study.

\section{Funding}

The research grant provided by Research Deputy of Hormozgan University of Medical Sciences (HUMS). The role of the funding body was collection and analysis.

\section{Availability of data and materials}

The primary data for this study is available from the authors (FB) on direct request.

\section{Ethics approval and consent to participate}

All procedures performed in studies involving human participants were in accordance with the ethical standards of the institutional and/or national research committee and with the 1964 Helsinki Declaration and its later amendments or comparable ethical standards. The Ethics Committee of the Hormozgan Medical University approved the study (IR.hUMS.REC.1398.038). After presenting the purpose of the study to suitable participants who met the inclusion criteria, a written consent was obtained from each volunteer who was asked to complete the three measures.

\section{Consent for publication}

Not applicable

\section{Competing interests}

The authors report no conflicts of interest.

\footnotetext{
Author details

${ }^{1}$ Social Determinants of Health Research Center, Yasuj University of Medical Sciences, Yasuj, Iran. ${ }^{2}$ Department of Gynecology and Obstetrics, School of Medicine, Yasuj University of Medical Sciences, Yasuj, Yasuj, Iran. ${ }^{3}$ Fertility and Infertility Research Center, Hormozgan University of Medical Sciences, Bandar Abbas, Iran. ${ }^{4}$ Centre for Critical Research in Nursing and Midwifery, School of Health and Education, Middlesex University, London, UK. ${ }^{5}$ Student Research Committee, Hormozgan University of Medical Sciences, Bandar Abbas, Iran. ${ }^{6}$ Hazratezahra Infertility Center, Bandar Abbas, Iran. ${ }^{7}$ Medicinal Plants Research Center, Yasuj University of Medical Sciences, Yasuj, Iran.
}

Received: 10 August 2020 Accepted: 16 December 2020

Published online: 07 January 2021

\section{References}

1. Azziz R (2003) Androgen excess is the key element in polycystic ovary syndrome. Fertil Steril 80(2):252-254

2. Jalilian A et al (2015) Prevalence of polycystic ovary syndrome and its associated complications in Iranian women: a meta-analysis. Iran J Reprod Med 13(10):591-604

3. Kitzinger C, Willmott J (2002) "The thief of womanhood": women's experience of polycystic ovarian syndrome. Soc Sci Med 54(3):349-361

4. Himelein MJ, Thatcher SS (2006) Polycystic ovary syndrome and mental health: a review. Obstet Gynecol Surv 61(11):723-732

5. Eggers S, Kirchengast S (2001) The polycystic ovary syndrome--a medical condition but also an important psychosocial problem. Coll Antropol 25(2): 673-685

6. Elsenbruch S et al (2003) Quality of life, psychosocial well-being, and sexual satisfaction in women with polycystic ovary syndrome. J Clin Endocrinol Metab 88(12):5801-5807

7. De Frene $V$ et al (2015) Sexual and relational satisfaction in couples where the woman has polycystic ovary syndrome: a dyadic analysis. Hum Reprod 30(3):625-631

8. Amiri H, Rostaiyan E, Lary yazdi H, Ahghir Chehregani E. Recognition of compounds of essential oil of Stachys lavandulifolia Vahl and their untimicrobial effects. JSIAU 2009; 18(70):43-50.

9. Zargari A (1997) Labiatae. In: Iranian medicinal plants, 6th edn. Pub of Tehran University, Tehran, pp 127-133

10. ESHRE/ASRM: ESHRE/ASRM Rotterdam Consensus Meeting Revised 2003 consensus on diagnostic criteria and long-term health risks related to polycystic ovary syndrome (PCOS). Hum Reprod 2004, 19:41-47.

11. Amirjani $S$ et al (2019) Dietary intake and lifestyle behaviour in different phenotypes of polycystic ovarian syndrome: a case-control study. J Hum Nutr Diet. 32(4):413-421. https://doi.org/10.1111/jhn.12646 Epub 2019 Mar 11

12. Azizi Kutenaee $M$ et al (2020) The impact of depression, self-esteem, and body image on sleep quality in patients with PCOS: a cross-sectional study. Sleep Breath. 24(3):1027-1034. https://doi.org/10.1007/s11325-019-01946-9 Epub 2019 Oct 19

13. Bazarganipour $\mathrm{F}$ et al (2020) The impact of irritable bowel syndrome on health-related quality of life in women with polycystic ovary syndrome. Health Quality Life Outcomes 18(1):226

14. Drosdzol A et al (2007) Quality of life and marital sexual satisfaction in women with polycystic ovary syndrome. Folia Histochem Cytobiol 45(1): S93-S97

15. Baweja R et al (1985) Indian Council of Medical Research. Task Force on Hormonal Contraception: Phase II randomized clinical trial with norethisterone oenanthate $50 \mathrm{mg}$ alone and in combination with $5 \mathrm{mg}$ or $2.5 \mathrm{mg}$ of either estradiol valerate or cypionate as a monthly injectable contraceptive. Contraception 32(4):383-394

16. Ferrimanm D, Gallwey JD (1961) Clinical assessment of body hair growth in women. J Clin Endocrinol Metab 21:1440-1447

17. Lever, W.F. and G. Schaumburg-Lever, Acne vulgaris. Histopatbology of the Skin. $7^{\text {th }}$ edn. Philadelphia: JB Lippincott, 1990: 218-219.

18. Rosen R, B.C., Heiman J, Leiblum S, Meston C, Shabsigh R, et al, The Female Sexual Function Index (FSFI): a multidimensional self-report instrument for the assessment of female sexual function. J Sex Marital Ther, 2000. 26(2): 191-208.

19. MOHAMMADI KH, HEYDARI M, FAGHIHZADEH S (2008) THE FEMALE SEXUAL FUNCTION INDEX (FSFI): VALIDATION OF THE IRANIAN VERSION. PAYESH 7(3):269-278

20. Sanaei B (2000) Marriage and Family Assessment Scale. Tehran, Verayesh editing

21. Shahvary Z, Gholizadeh L, Mohammad Hosieny S (2010) Determination of some related factors on women sexual satisfaction Gachsaran (south west of Iran). J Gorgan Uni Med Sci. 11(4):51-56

22. Shahsiah M, Bahrami F, Mohebi S (2009) On the relationship between sexual satisfaction and marital commitment among couples in Shahreza city, central part of Iran. J Fundam Ment Health. 11(43):233-238

23. Rosen RC et al (1997) The international index of erectile function (IIEF): a multidimensional scale for assessment of erectile dysfunction. Urology 49(6):822-830 
24. World Health Organization (2015) WHO global disability action plan 20142021: better health for all people with disability. World Health Organization https://apps.who.int/iris/handle/10665/199544

25. Mansson M et al (2011) Sexuality and psychological wellbeing in women with polycystic ovary syndrome compared with healthy controls. Eur $J$ Obstet Gynecol Reprod Biol 155(2):161-165

26. Kowalczyk R et al (2015) Sexuality in women with polycystic ovary syndrome. Ginekol Pol 86(2):100-106

27. Hashemi $S$ et al (2014) Association of PCOS and its clinical signs with sexual function among Iranian women affected by PCOS. J Sex Med 11(10):25082514

28. Bazarganipour $F$ et al (2014) Health-related quality of life in patients with polycystic ovary syndrome (PCOS): a model-based study of predictive factors. J Sex Med 11(4):1023-1032

29. Winkvist A, Akhtar HZ (2000) God should give daughters to rich families only: attitudes toward childbearing among low-income women in Punjab. Pakistan. Soc Sci Med 51:73-78

30. Salmela-Aro K, Suikkari AM. Letting go of your dreams-adjustment of childrelated goal appraisals and deppresive symptoms during infertility treatment. J Res Personal. 2008; 22: (42): 988-1003. doi: https://doi.org/10 1016/j.jp. 2008.02.007.

31. Younesi SJ, Salagegheh A (2001) Body image in fertile and infertile women. J Reprod Infertil. 2(4):14-21

32. Abbasi Molid H (2012) Reza Zadeh varaghchi J. Psychological meta-analysis of the infertility researches in Iran. IJOGI. 15(13):16-33

33. Barua A, Pande R, Kurz K, Walia S, MacQuarrie K, Jain S (2006). Addressing Gender-Based Constraints in Youth Reproductive Health: Experiences and Behaviors about Infertility among Young Couples in Rural Maharashtra, India. Foundation for Research in Health Systems (FRHS), International Center for Research on Women (ICRW). Avalible at https://www.icrw.org/ publications/improving-the-reproductive-health-of-married-and-unmarriedyouth-in-india/.

34. Riahi ME, Zarezade Mehrizi E. A study on the gender differences in psychosocial consequences of infertility: Infertile couples using Yazd' Infertility Center services. Womens Strategic Studies. 2012; 14 (56): 155-210.

35. Nilforooshan P, Ahmadi SA, Abedi MR, Ahmadi SM (2006) Attitude towards infertility and its relation to depression and anxiety in infertile couples. J Reprod Infertil. 6(5):546-552

36. Fahami F, Hoseini Quchani S, Ehsanpour S, Zargham A (2010) Women's lived experiences of female infertility. IOG I. 4(30):45-53

37. Behdani F, Erfanian M, Hebrani P, Hojat SK (2004) Prevalence of depression and related factors in infertile women. J Fundam Ment Health. 6(23-24):141-146

38. Abbasi-Shavazi MJ, Razeghi H, Behjati Z, Akhondi M (2006) Attitudes of infertile women towards gamete donation: a case study in Tehran. J Reprod Infertil. 7(2):139-148

39. Faal Kalkhoran L, Bahrami H, Farrokhi NA, Zeraati H, Tarahomi M (2011) Comparing anxiety, depression and sexual life satisfaction in two groups of fertile and infertile women in Tehran. J Reprod Infertil. 12(2):157-162

40. Millheiser LS et al (2010) Is infertility a risk factor for female sexual dysfunction? A case-control study. Fertil Steril 94(6):2022-2025

41. Iris A, Aydogan Kirmizi D, Taner CE (2013) Effects of infertility and infertility duration on female sexual functions. Arch Gynecol Obstet 287(4):809-812

42. Song SH et al (2016) Sexual function and stress level of male partners of infertile couples during the fertile period. BJU Int 117(1):173-176

43. Stovall DW et al (2012) Sexual function in women with polycystic ovary syndrome. J Sex Med 9(1):224-230

\section{Publisher's Note}

Springer Nature remains neutral with regard to jurisdictional claims in published maps and institutional affiliations.

\section{Submit your manuscript to a SpringerOpen ${ }^{\circ}$ journal and benefit from:}

- Convenient online submission

- Rigorous peer review

- Open access: articles freely available online

- High visibility within the field

- Retaining the copyright to your article

Submit your next manuscript at $\boldsymbol{\nabla}$ springeropen.com 